\title{
Developmental and environmental variation in genomes
}

\author{
X-Q Li \\ Potato Research Centre, Agriculture and Agri-Food Canada, New Brunswick, Canada
}

\begin{abstract}
The genetic make-up of an organism, established at fertilization, is not conventionally expected to change during development unless mutation occurs. However, there is actually evidence that considerable variation can arise. Some of these changes may occur in response to the environment. This article reviews such variations in genome size or DNA content (excluding ploidy-level changes). The variation can be generated by processes, including high-frequency chromosomal recombination, transposition, cis-element-enhanced gene amplification and repetitivesequence-based changes in nuclear DNA content. Environmentally induced and developmentally regulated genomic variation (ED-genomic variation or ED-genetic variation) can be found in both coding and non-coding sequences, and is often non-Mendelian in its inheritance pattern. Changes can depend on development (for example, propagation method, seed/fruit position on plants, embryo stage, etc.) and occur in response to the environment (for example,
\end{abstract}

light, temperature, herbicide, salinity, fertilizer, land slope direction, pathogen infection, etc.). Some plants have meiotic (or rejuvenation) corrections, which restore their genome sizes to a certain degree. However, Mendelian inheritance and acquired inheritance of the variants occur, and both inheritance types may be different expressions evolved for the same adaptive responses. With this perspective, the terms 'pure-breeding line' or 'stable cultivar' may only be appropriate for a given mode of reproduction or propagation, and for a given environment. ED-genomic variation appears to be an essential component of differentiation, development and adaptation. Consequently, modern molecular biology tools, such as microarray hybridization and new sequencing technology, should be directed towards a more comprehensive evaluation of ED-genomic variation.

Heredity (2009) 102, 323-329; doi:10.1038/hdy.2008.132; published online 14 January 2009

Keywords: somatic cells; somagenetics; genome plasticity; gene amplification; repetitive DNA; adaptation

\section{Introduction}

Organisms depend on genetic variation to respond to novel environmental challenges. Meiotic segregation is the best-studied mechanism generating such variations in the genotype. However, genomic plasticity occurring during somatic growth and in response to environmental conditions has also been widely documented (Cullis, 1981; De Paepe et al., 1982; Price and Johnston, 1996; Waters and Schaal, 1996). Genetic tools are now sensitive enough to monitor and assess this plasticity. This new genetic knowledge will profoundly impact on both theoretical and applied biology.

The literature on DNA content variation of plants before the time of high throughput DNA sequencing (up to 1988) has been documented and analyzed (Bassi, 1990). It is time to re-evaluate this topic in light of considerably improved technology and the new data accumulated over the last 20 years. The emphasis of this discussion is on plants, although relevant discoveries from animals and microorganisms are also briefly discussed.

Correspondence: $\mathrm{Dr} X-Q \mathrm{Li}$, Potato Research Centre, Agriculture and Agri-Food Canada, 850 Lincoln Road, PO Box 20280, Fredericton, New Brunswick, Canada E3B $4 Z 7$.

E-mails: Xiu-Qing.Li@AGR.GC.CA or lixiuqing2008@gmail.com Received 1 December 2007; revised 18 August 2008; accepted 4 December 2008; published online 14 January 2009
Several recent reviews and commentaries have covered the following areas: the technical limitations of Feulgen cytometry in nuclear DNA amount estimation (Nardon et al., 2003; Greilhuber, 2008), phenotypic impacts of repetitive DNA in flowering plants (Meagher and Vassiliadis, 2005), rapid changes in plant genomes (Henikoff, 2005), the types of somagenetic variations that usually do not change the genome size ( $\mathrm{Li}, 2008)$ and nuclear gene-induced mitochondrial DNA variation (Abdelnoor et al., 2003; Albert et al., 2003). This review gives emphasis to the variation that affects the nuclear genome size or DNA content. To avoid confusion with genomic variation arising from meiotic chromosomal crossover and allele segregation, this article mainly reviews the literature on environmentally and developmentally induced genomic variation (ED-genomic variation or ED-genetic variation) during somatic growth.

\section{Development-induced DNA content variation}

There are several reports of variation in DNA during development, or associated with different modes of reproduction. Such changes can be detected in homozygous or relatively homozygous genotypes.

Nicotiana sylvestris, a selfing diploid species, showed increased DNA content and quantitative morphological variation in doubled haploid $(\mathrm{DH})$ homozygote plants obtained from consecutive pollen (microspore) culture 
cycles (that is, using the pollen of pollen-derived $\mathrm{DH}$ plants for culture) (De Paepe et al., 1981, 1982, 1983). The pollen culture medium did not contain any plant growth regulators. The average leaf size decreased regularly up to the fifth consecutive culture cycle. From the fifth to the seventh cycle, there were new morphological changes seen, such as foliar outgrowths from leaf veins, even though DH plants were homozygous. Both in vivo labeled (methyl-3H) and unlabeled DNA were analyzed. Reassociation kinetic curves showed that the highly repetitive DNA content increased regularly from the original line to the double haploid plants of the fifth cycle. Data from Feulgen cytophotometry of root-tip squashes showed that they contained $10 \%$ more DNA on the average than plants of the original line; yet they did not have any detectable changes in their chromosomal complement. As the DH plants originated from the haploid vegetative cells in the pollen, the results might suggest a difference between the vegetative cells and the generative cells in the pollen during cellular differentiation (De Paepe et al., 1981). The distinction might correspond to the differences in DNA organization known to exist between macro- and micro-nuclei of ciliated protozoa (Lauth et al., 1976).

In contrast to these differences attributed to the nuclear DNA, no cytoplasmic mutants were found in the DH plants, although three individual plants with mitochondrial DNA variation were detected in plants regenerated from the second cycle of protoplast culture in the same line of N. sylvestris (Li et al., 1988). A similar nuclear DNA content increase in anther-derived dihaploid plants was also detected using cytophotometric analysis and thermal denaturation kinetics in Nicotiana tabacum (Dhillon et al., 1983).

In sunflower (Helianthus annuus), analysis of nuclear DNA content in differentiated tissues of nine cultivars, comprising hybrids and selfed lines, revealed that the nuclear DNA content of differentiated G1 cells increased or decreased, and did not exactly match the $2 \mathrm{C}$ DNA content found in meristematic cells. This survey used scanning cytophotometry following Feulgen staining (Cavallini and Cionini, 1986). Variation is also found within sunflower plants. Natali et al. (1993) compared seedlings obtained from sunflower seeds (achenes) collected at the periphery (P-seedlings) and those in the middle (M-seedlings) of the flowering heads of plants of a line repeatedly selfed for 10 years. The nuclear DNA content of P-seedlings was $14.7 \%$ greater than that of M-seedlings in cytophotometric analysis. Thermal denaturation and reassociation kinetics of extracted DNA implicated differences in the repetitive DNA. Slot-blot molecular hybridizations indicated a greater amount of ribosomal DNA in the P-seedlings compared with the M-seedlings. The mitotic cycle time of cell proliferation was longer in the high DNA content P-seedlings than in the M-seedlings. The differences in nuclear DNA content and organization may play a role in determining the developmental variability within sunflower populations.

There are comparable reports from animal studies. Developmentally regulated amplification of chorion genes has been found during oocyte development in silkworms (Bombyx mori) (Kafatos et al., 1985) and Drosophila (Drosophila melanogaster) (Delidakis and Kafatos, 1989). An alternative type of change occurs in ciliates in the genera Oxytricha and Stylonychia; they have both a somatic nucleus and a zygotic germline nucleus. After sexual conjugation, a new somatic nucleus forms from the new zygotic germline nucleus. Formation of the somatic nucleus involves a developmental process that precisely eliminates a large portion of DNA sequences from the germline (Lauth et al., 1976; Mollenbeck et al., 2006).

The studies reviewed in this section shows that the genome size varies during development. The repetitive sequences appear to be more involved in EDgenomic variation than the non-repetitive sequences. It is unclear whether this perceived trend is because changes in the repetitive sequences are more readily detected, or is real. This problem should be resolved as genomic approaches are used to evaluate all the regions of the genome.

\section{Environment-induced DNA content variation}

Several flax (Linum usitatissimum) varieties have been shown to undergo environmentally induced heritable changes (that is, changes induced by combinations of different fertilizers of nitrogen, phosphate, potash and calcium), resulting in stable lines termed genotrophs (Durrant, 1962a,b). The cultivar Stormont Cirrus can generate both large and small genotrophs. The changes are unlikely to have come from natural residual heterozygosity of the original lines. Large genotrophs have $16 \%$ more DNA than small genotrophs as judged by Feulgen photometry (Evans et al., 1966). Slot blotting hybridization was used to study the variation of highly repetitive tandem array sequences. Although the variation has been shown to be spread throughout the genome, the copy number of the $5 S$ ribosomal RNA gene of these genotrophs was found to be changed (Cullis, 1981, 2005). The changes occurred within a relatively short period of vegetative growth (Cullis, 2005).

Restriction fragment length polymorphisms were observed in both large and small genotrophs. Identical restriction fragment length polymorphism profiles were observed in four small genotrophs produced from separate environmental induction experiments. The polymorphisms were all produced from a repetitive $5 S$ ribosomal RNA gene cluster, at a single chromosomal locus. Similar, but not identical, polymorphisms were also detected in other flax varieties and Linum species suggesting that the induced variation is related to that which occurs naturally (Schneeberger and Cullis, 1991).

In sunflower (H. annuus), the light-induced 2C DNA content variation of nuclei isolated from the first leaf pair of seedlings grown in greenhouses and growth chambers with increased levels of substrate nitrogen, in the form of $\mathrm{NH}_{4} \mathrm{NO}_{3}$, has been measured using laser flow cytometry (Johnston et al., 1996). DNA content of greenhousegrown seedlings was found to be highly variable and was influenced by light quantity and/or quality (Johnston et al., 1996). In a similar experiment, sunflowers were grown in vermiculite and saturated every other day with a solution containing trace elements, 45 p.p.m. nitrogen, 48 p.p.m. phosphorous and 51 p.p.m. potassium. The instability of DNA content, particularly for plants grown under far red-rich light, suggests that phytochromes may be involved in regulating DNA content of the sunflower (Price and Johnston, 1996). 
As leaves could have different amount of secondary products, such as polyphenols, there is some concern that the reported variation in DNA content may be partly because of the differential accumulation of one or more secondary products in leaves, which interfere with the intercalation and/or fluorescence of propidium iodide (Price et al., 1998).

Brassica nigra DNA content variation after heat shock treatment has been detected using the slot-blot hybridization method (Waters and Schaal, 1996). No effects of heat shock on the copy number of the single-copy nuclear genes or chloroplast DNA were found, but the heat shock caused a statistically significant reduction in $5 S$ ribosomal RNA gene copies.

Festuca arundinacea DNA content has been measured by several approaches using seedlings germinated and growing at 10,20 , or $30^{\circ} \mathrm{C}$ (Ceccarelli et al., 1997). Feulgen/DNA cytophotometric measurement showed the greatest increase and decrease in absorption from seedlings at 30 and $10{ }^{\circ} \mathrm{C}$, respectively. Slot-blot molecular hybridization results indicated that the redundancy of repeated DNA sequences belonging to two families was significantly greater in the genome of the seedlings grown at $30^{\circ} \mathrm{C}$ than those grown at $10^{\circ} \mathrm{C}$. These results provide evidence that these genomic domains are capable of rapid, quantitative alterations in response to developmental and environmental stimuli (Ceccarelli et al., 1997). In these experiments, the Feulgen/DNA cytophotometric estimations of genome size in the seedling meristem are in agreement with the results from molecular hybridization and radioactive labeling approaches.

Instability of somatic genomes, apparently linked to environments or propagation conditions, has been also reported in human and some animals. Monozygotic human twins display different DNA copy-numbervariation profiles (Bruder et al., 2008). Extensive and recurrent copy number variations of DNA segments occur in mouse embryonic stem cell subclones (Liang et al., 2008).

As DNA variation measured by Feulgen cytophotometry has been validated by molecular hybridization approaches (De Paepe et al., 1982; Natali et al., 1993; Ceccarelli et al., 1997), it remains one of the most useful approaches to studying DNA content variation, as long as cell types, experimental designs and controls are appropriate.

These studies indicate that the genome size varies in response to environment. Although different mechanisms may apply to different cases, it is likely that some gene amplification enhancers/activators are more active under certain stressful conditions. In future studies, transgenic approaches may be useful to test the responses of cis-enhancers to different stresses. Mutation screening using marker genes in transgenic plants be used to detect cis- or trans-factors.

\section{Stability and function of developmentally changed DNA content}

There is evidence of a meiotic correction of DNA content in the DH plants of $N$. sylvestris (Li, 1983). The DH lines showed a tendency to return to the DNA amount found in the original line when propagated by selfing. Within two generations, the DNA content converged on a control line, which had been propagated by selfing from the original line (that is, without microspore culture used to form the DH lines). These results suggest that, at least in N. sylvestris DH plants, the developmentally induced DNA content is unstable under reproduction by selfing.

In carrot, the slot-blot hybridization assay has been used to study the DNA content over different culture time points on 2,4-dichlorophenoxyacetic acid-containing medium. Both medium repetitive and unique sequences probed consistently showed a reduction in DNA levels during the acquisition of embryogenic competence. In some cases, the cultured cells contained only $10 \%$ of the gene copies observed in the reference tissues. However, DNA levels of most sequences were recovered at the torpedo-embryonic stage (Geri et al., 1999). It is unclear how the quantity of unique sequences can change. One speculation is that changes in the repetitive sequences increased the relative DNA content.

It has been speculated that DNA content and associated DNA changes may be an adaptation to the abiotic and biotic environmental stresses that the plant is exposed to. In Silene latifolia, DNA content is negatively correlated with flower size (Meagher and Vassiliadis, 2005). In wild diploid peanut (Arachis duranensis), there is a negative correlation of genome size with latitude and altitude above sea level of the collection sites, according to flow cytometry analysis (Temsch and Greilhuber, 2001).

In the case of $N$. sylvestris, it appears that the increased DNA content in $\mathrm{DH}$ plants is a by-product of the vegetative cells in the pollen. The increase in DNA content may assist the cells in providing sufficient metabolic support to the generative cells in the same pollen during pollen germination, but it is unnecessary at the plant growth stage. The DNA content in DH plants tends to return to the normal level but the morphological traits, such as plant size and leaf size, are still much smaller than those of their wild type original plants (Li, 1983)

\section{Molecular processes relevant to DNA content variation}

It has been established that amplification of a gene cluster in D. melanogaster is controlled by a cis-acting element upstream of the gene (De Cicco and Sprading, 1984; Spradling et al., 1987). Similarly, the existence of a cis-enhancer responsible for the increase in the gene copy number in tobacco ( $N$. tabacum) has been confirmed by genetic transformation (Borisjuk et al., 2000). The cis-acting genetic element was isolated from the non-transcribed spacer region of tobacco ribosomal DNA, and it can increase the copy number and expression of genes immediate downstream, such as an herbicide resistance gene. Both the increased transgene copy number and its enhanced expression were stably inherited. Despite this heritable effect, as most genes in the genomes of most species are relatively stable, there must be an evolutionary mechanism that allows only certain genomic regions or genes to be more flexible than others.

A different type of change appears to be the consequence of DNA replication slippage, which can induce the expansion or deletion of nucleotide repeats during DNA replication by DNA polymerase I (Kappen et al., 2003). The rate of change can be modified; several 
mutagens, such as X-rays, tryptophan pyrolysate and acetylaminofluorene, can induce a high frequency of deletions at the sites of short direct repeats in mammalian cells. In colorectal tumor cells, about $40 \%$ of the mutations are deletions at the sites of short repeats (Kimura et al., 1994).

Another distinctive process affecting genome size is DNA transposition, initially discovered in maize by McClintock (1962). There are many types of transposons, yet sometimes, a single type of retrotransposon can comprise a large percent of the total DNA content in the plant genome (Stergiou et al., 2002), for example, retrotransposons are quite abundant throughout the citrus genome (Asins et al., 1999). Transposition can be enhanced by environmental factors such as ionizing radiation (Sacerdot et al., 2005), fungal infection or fungal extracts (Melayah et al., 2001). The behavior of Tnt1 retrotransposons differs between host species, most probably in correlation with differences in expression conditions, and in the evolutionary and environmental history of each host (Grandbastien et al., 2005). Retrotransposition-driven genomic expansions in a wild relative of rice may have doubled the genome size without polyploidization (Piegu et al., 2006). Haniford (2006) provides a useful review of the transpososome and regulation in T10-type transposition.

Induced unequal mitotic recombination is another mechanism affecting DNA content (Ayaki et al., 1990). However, as unequal recombination generates one cell with less amount of DNA and another with more amount of DNA, the total DNA in the plant would not be significantly changed unless the organism's further development is more reliant on the derivatives of one of the cells with altered DNA content.

During development, the genome also undergoes processes such as the high gene conversion rate detected in Phytophthora sojae (Chamnanpunt et al., 2001) or immunoglobulin gene diversification in animals (McCormack et al., 1991). However, these changes appear unlikely to contribute significantly to the increase or decease of genomic DNA content.

\section{Adaptive effects}

At least in the cases where ED-genomic changes appear regularly, or as a result of a controlled molecular mechanism, it seems reasonable to suggest that they provide adaptive benefits. Cavalier-Smith (2005) suggests relationships between DNA content, cell size and mitotic rhythm. A significant inverse correlation between genome size and developmental rate has been found in five freshwater cyclopoid species at three temperatures, that is, species with smaller genomes developed faster (Wyngaard et al., 2005). In hexaploid F. arundinacea, DNA content is positively correlated with mitotic time and flowering time (Ceccarelli et al., 1993). The genome sizes of $F$. arundinacea natural populations correlate positively with the mean temperature during the year and with that of the coldest month at the stations (Ceccarelli et al., 1993). Both cell proliferation in the shoot meristems and cell enlargement in differentiated tissues are affected by the genome size; for example, the basic amount of nuclear DNA is negatively correlated with the height of the main stem of the Vicia faba plants at anthesis (Minelli et al., 1996).
Genera with large genomes are less likely to have many species. Species with large genomes at the $1 \mathrm{C}$ DNA content level have reduced maximum photosynthetic rates, suggesting that large genomes might constrain plant performance (Knight et al., 2005). Further investigation is required to increase our understanding of why certain species have very large genomes, and why certain tissues increase their DNA contents during development or in response to the environment.

The sequence rearrangement and segment loss is very common, and leads to new genomes that are not exactly the sum of the previous ones in plants during diploidization after interspecific hybridization (Wang et al., 2005; Paun et al., 2007; Bento et al., 2008). Both diploidizationinduced genome size changes and ED-genome-induced changes are sources of genetic variation, and can contribute to the adaptation and evolution.

\section{Agricultural impact of DNA variation and genome plasticity}

The DNA content, transposition activity and recombination rate are known to be influenced by factors, which include, the type of cells used in propagation (De Paepe et al., 1982), seed position on the sunflower head (Natali et al., 1993) and environmental factors such as fertilizers (Cullis and Cleary, 1986), herbicides (Besplug et al., 2004), UV-B radiation (Ries et al., 2000), $\mathrm{NaCl}$ salt content in growth medium (Puchta et al., 1995) and light intensity (Price and Johnston, 1996). For example, in barley (Hordeum spontaneum), on a drier south-facing slope, BARE-1 retrotransposon copy number increases (Kalendar et al., 2000). Ceratonia siliqua trees have microgeographic genome size differentiation, suggesting an ED-genomic involvement (Bures et al., 2004). In most situations, crop cultivars are selected to be relatively stable under propagation by 'regular' methods and to have relatively constant performance under conventional farming conditions. To ensure the reproducibility of farming performance and crop quality, and to minimize crop variation due to genomic changes, it is better not to treat the plants with atypical stress during in vitro maintenance and seed development if the seed or plantlets are for commercial planting.

Domestication is an on going process, as no cultivar is prefect. Even if the environment were nearly stable at the year-to-year level, genome plasticity could allow adaptation to shorter-term environment change. For agronomic traits, as adaptation and domestication are not necessarily on the same direction, a human selection may have to be sufficiently strong to overcome certain unfavorable adaptation, to further the domestication of crops.

\section{Future research trends}

Although the studies discussed in this review are mainly on somagenetic variation (changes of DNA sequence in somatic cells), sexual reproduction is also likely to be subject to ED-genomic variation. The tendency of DNA content in $\mathrm{DH} N$. sylvestris to revert to control levels (Li, 1983) suggests a hypothesis of meiosis correctiona developmental correction-in genome size during meiosis. As genotypes are largely stable over the generations, there may be a genomic variation cycle in some organisms: starting (time zero) when a zygote is formed; changing 
during cell differentiation, individual development and in response to the environment, and returning to time zero with meiotic correction when the next generation's zygote is formed. Such a cycle may have an important relationship with rejuvenation, particularly for vegetatively propagated plants in horticulture and sylviculture. A zygote seems likely to be the most rejuvenated type of tissue. The precise molecular mechanisms of this hypothesized meiotic correction and genomic generation cycle remains to be clarified.

The existence of such a regulated cycle could be investigated by molecular hybridizations (blot- or macroor micro-array), long-run sequencing and denaturing analysis of DNA isolated from different types of cells. The challenge will be the isolation of the microspore vegetative cell, microspore generative cell, egg, zygote and early stage embryos from the same clonal line, ideally the same plant. If there is an ED-genomic variation during the reproductive phase, it may be confounded by the effects of chromosomal meiotic crossover and allele segregation, and make the molecular analysis difficult. Specially designed experiments are required to separate the ED-genomic variation from classical meiotic variation.

Current genome projects center on coding sequences. The experimental designs of such projects are not compatible with investigation of the kind of variation described in this paper. Specially designed research is required to survey the variation at the whole genome sequence level to understand its molecular and physiological mechanisms, and to study their potential use.

The newest genomic technologies, such as DNA microarray analysis and nanotechnology-level DNA sequencing, are most promising. An exon-level resolution microarray encompassing 57 selected genes has already been used successfully to identify a number of genes with DNA copy number alternations in neurofibromatosis cells (Mantripragada et al., 2008). In the future, similar microarray approaches might yield information on genome plasticity during development and under different conditions in various organisms.

The whole genomes of several people have now been fully sequenced (Levy et al., 2007). Techniques involving whole-genome sequencing and whole-population sequencing (metagenomics) are beginning to revolutionize the study of ecology and evolution in the bacteria (Hudson, 2008). The newest generation sequencing nanotechnologies, such as Solexa/Illumina (http://www.illumina.com; San Diego, CA, USA) reversible terminator technologies and polony sequencing (http://www.polonator.org; Salem, $\mathrm{NH}$, USA), still have difficulties in dealing with repeat sequences. If this problem can be solved through bioinformatic or integrated approaches, it would be feasible to sequence and compare whole genome versions at different developmental stages, under different stresses or different tissues of the same person or plant.

We are only at the beginning of the discovery of mechanisms, behavior, impact, and application of the environmentally and developmentally regulated genomic variation. Further research is required to understand the cytogenetic, DNA-structural and gene-regulation basis of ED-genomic variation, and to study the importance of ED-genomic variation for population genetics, adaptation, domestication, evolution, medical science, plant science and agriculture.

\section{Acknowledgements}

I thank Professor Danielle Donnelly for her critical reading of an early version of this article, and Professors Richard Nichols and Christian Biémont and the two anonymous reviewers for their valuable suggestions.

\section{References}

Abdelnoor RV, Yule R, Elo A, Christensen AC, Meyer-Gauen G, Mackenzie SA (2003). Substoichiometric shifting in the plant mitochondrial genome is influenced by a gene homologous to MutS. Proc Natl Acad Sci USA 100: 5968-5973.

Albert B, Lelandais C, Pla M, Leuret C, Vitart V, Mathieu C et al. (2003). Amplification of Nicotiana sylvestris mitochondrial subgenomes is under nuclear control and is associated with phenotypic changes. Genetica 117: 17-25.

Asins MJ, Monforte AJ, Mestre PF, Carbonell EA (1999). Citrus and Prunus copia-like retrotransposons. Theor Appl Genet 99 503-510.

Ayaki T, Fujikawa K, Ryo H, Itoh T, Kondo S (1990). Induced rates of mitotic crossing over and possible mitotic gene conversion per wing anlage cell in Drosophila melanogaster by $X$ rays and fission neutrons. Genetics 126: 157-166.

Bassi P (1990). Quantitative variations of nuclear DNA during plant development: a critical analysis. Biol Rev 65: 185-225.

Bento M, Pereira HS, Rocheta M, Gustafson P, Viegas W, Silva M (2008). Polyploidization as a retraction force in plant genome evolution: sequence rearrangements in triticale. PLOS ONE 3 : e1402.

Besplug J, Filkowski J, Burke P, Kovalchuk I, Kovalchuk O (2004). Atrazine induces homologous recombination but not point mutation in the transgenic plant-based biomonitoring assay. Arch Environ Contam Toxicol 46: 296-300.

Borisjuk N, Borisjuk L, Komarnytsky S, Timeva S, Hemleben V, Gleba Yet al. (2000). Tobacco ribosomal DNA spacer element stimulates amplification and expression of heterologous genes. Nat Biotechnol 18: 1303-1306.

Bruder CEG, Piotrowski A, Gijsbers AACJ, Andersson R, Erickson S, Diaz de Stahl T et al. (2008). Phenotypically Concordant and Discordant Monozygotic Twins Display Different DNA Copy-Number-Variation Profiles. Am J Hum Genet 82: 763-771.

Bures P, Pavlicek T, Horova L, Nevo E (2004). Microgeographic genome size differentiation of the carob tree, Ceratonia siliqua, at 'Evolution Canyon', Israel. Ann Bot 93: 529-535.

Cavalier-Smith T (2005). Economy, speed and size matter: evolutionary forces driving nuclear genome miniaturization and expansion. Ann Bot 95: 147-175.

Cavallini A, Cionini PG (1986). Nuclear DNA content in differentiated tissues of sunflower (Helianthus annuus L.). Protoplasma 130: 91-97.

Ceccarelli M, Giordani T, Natali L, Cavallini A, Cionini PG (1997). Genome plasticity during seed germination in Festuca arundinacea. Theor Appl Genet 94: 309-315.

Ceccarelli M, Minelli S, Falcinelli M, Cionini PG (1993). Genome size and plant development in hexaploid Festuca arundinacea. Heredity 71: 555-560.

Chamnanpunt J, Shan WX, Tylert BM (2001). High frequency mitotic gene conversion in genetic hybrids of the oomycete Phytophthora sojae. Proc Natl Acad Sci USA 98: 14530-14535.

Cullis CA (1981). Environmental induction of heritable changes in flax: defined environments inducing changes in rDNA and peroxidase isozyme band pattern. Heredity 47: 87-94.

Cullis CA (2005). Mechanisms and control of rapid genomic changes in flax. Ann Bot 95: 201-206.

Cullis CA, Cleary W (1986). Rapidly varying DNA sequences in flax. Can J Genet Cytol 28: 252-259. 
De Cicco DV, Sprading AC (1984). Localization of a cis-acting element responsible for the developmentally regulated amplification of Drosophila chorion genes. Cell 38: 45-54.

De Paepe R, Bleton D, Gnangbe F (1981). Basis and extent of genetic variability among doubled haploid plants obtained by pollen culture in Nicotiana sylvestris. Theor Appl Genet 59: 177-184.

De Paepe R, Prat D, Huguet T (1982). Heritable nuclear DNA changes in doubled haploid plants obtained by pollen culture of Nicotiana sylvestris. Plant Sci Lett 28: 11-28.

De Paepe R, Prat D, Knight J (1983). Effects of consecutive androgenesis on morphology and fertility in Nicotiana sylvestris. Can J Bot 61: 2038-2046.

Delidakis C, Kafatos FC (1989). Amplification enhancers and replication origins in the autosomal chorion gene cluster of Drosophila. EMBO J 8: 891-901.

Dhillon SS, Wernsman EA, Miksche JP (1983). Evaluation of nuclear DNA content and heterochromatin changes in anther-derived dihaploids of tobacco (Nicotiana tabacum) $\mathrm{cv}$. Coker I 39. Can J Genet Cytol 25: 169-173.

Durrant A (1962a). The environmental induction of heritable change in Linum. Heredity 17: 27-61.

Durrant A (1962b). Induction, reversion and epitrophism of flax genotrophs. Nature 196: 1302-1304.

Evans GM, Durrant A, Rees H (1966). Associated nuclear changes in the induction of flax genotrophs. Nature 212: 697-699.

Geri C, Turrini A, Giorgetti L, Nicoletti E, Ronchi VN (1999). Genome plasticity during the acquisition of embryogenic competence. Genome 42: 1134-1143.

Grandbastien MA, Audeon C, Bonnivard E, Casacuberta JM, Chalhoub B, Costa APP et al. (2005). Stress activation and genomic impact of Tnt1 retrotransposons in Solanaceae. Cytogenet Genome Res 110: 229-241.

Greilhuber J (2008). Cytochemistry and C-values: the less-wellknown world of nuclear DNA amounts. Ann Bot 101: 791-804.

Haniford DB (2006). Transpososome dynamics and regulation in Tn10 transposition. Crit Rev Biochem Mol Biol 41: 407-424.

Henikoff S (2005). Rapid changes in plant genomes. Plant Cell 17: $2852-2855$.

Hudson ME (2008). Sequencing breakthroughs for genomic ecology and evolutionary biology. Mol Ecol Notes 8: 3-17.

Johnston JS, Jensen A, Czeschin Jr DG, Price HJ (1996). Environmentally induced nuclear 2C DNA content instability in Helianthus annuus (Asteraceae). Am J Bot 83: 1113-1120.

Kafatos FC, Mitsialis SA, Spoerel N, Mariani B, Lingappa JR Delidakis C (1985). Studies on the developmentally regulated expression and amplification of insect chorion genes. Cold Spring Harb Symp Quant Biol 50: 537-547.

Kalendar R, Tanskanen J, Immonen S, Nevo E, Schulman AH (2000). Genome evolution of wild barley (Hordeum spontaneum) by BARE-1 retrotransposon dynamics in response to sharp microclimatic divergence. Proc Natl Acad Sci USA 97: 6603-6607.

Kappen LS, Xi Z, Jones GB, Goldberg IH (2003). Stimulation of DNA strand slippage synthesis by a bulge binding synthetic agent. Biochemistry 42: 2166-2173.

Kimura H, Iyehara-Ogawa H, Kato T (1994). Slippage-misalignment: to what extent does it contribute to mammalian cell mutagenesis? Mutagenesis 9: 395-400.

Knight CA, Molinari NA, Petrov DA (2005). The large genome constraint hypothesis: evolution, ecology and phenotype. Ann Bot 95: 177-190.

Lauth MR, Spear BB, Heumann J, Prescott DM (1976). DNA of ciliated protozea: DNA sequence diminution during macronuclear development in Oxytricha. Cell 7: 57-74.

Levy S, Sutton G, Ng PC, Feuk L, Halpern AL, Walenz BP et al. (2007). The diploid genome sequence of an individual human. PLoS Biol 5: 2113-2144.

Li XQ (1983). Analysis of the evolution and nature of DNA content changes induced by androgenesis in Nicotiana sylvestris Spegaz and Comes. DEA thesis, University of Paris-Sud, Orsay, France.
Li XQ (2008). Nature, extent and developmental regulation of somagenetic variations. CAB Rev Perspect Agric Vet Sci Nutr Nat Resour 3: e31.

Li XQ, Chetrit P, Mathieu C, Vedel F, De Paepe R, Remy R et al. (1988). Regeneration of cytoplasmic male sterile protoclones of Nicotiana sylvestris with mitochondrial variations. Curr Genet 13: 261-266.

Liang Q, Conte N, Skarnes WC, Bradley A (2008). Extensive genomic copy number variation in embryonic stem cells. Proc Natl Acad Sci USA 105: 17453-17456.

Mantripragada KK, Spurlock G, Kluwe L, Chuzhanova N, Ferner RE, Frayling IM et al. (2008). High-resolution DNA copy number profiling of malignant peripheral nerve sheath tumors using targeted microarray-based comparative genomic hybridization. Clin Cancer Res 14: 1015-1024.

McClintock B (1962). Topographical relations between elements of control systems in maize. Carnegie Inst Wash Yr Bk 61: $448-461$.

McCormack WT, Tjoelker LW, Thompson CB (1991). Avian B-cell development: generation of an immunoglobulin repertoire by gene conversion. Annu Rev Immunol 9: 219-241.

Meagher TR, Vassiliadis C (2005). Phenotypic impacts of repetitive DNA in flowering plants. New Phytol 168: 71-80.

Melayah D, Bonnivard E, Chalhoub B, Audeon C, Grandbastien MA (2001). The mobility of the tobacco Tnt1 retrotransposon correlates with its transcriptional activation by fungal factors. Plant J 28: 159-168.

Minelli S, Moscariello P, Ceccarelli M, Cionini PG (1996). Nucleotype and phenotype in Vicia faba. Heredity 76: 524-530.

Mollenbeck M, Cavalcanti ARO, Jonsson F, Lipps HJ, Landweber LF (2006). Interconversion of germline-limited and somatic DNA in a scrambled gene. J Mol Evol 63: 69-73.

Nardon C, Weiss M, Vieira C, Biemont C (2003). Variation of the genome size estimate with environmental conditions in Drosophila melanogaster. Cytometry A 55: 43-49.

Natali L, Cavallini A, Cionini G, Sassoli O, Cionini PG, Durante M (1993). Nuclear DNA changes within Helianthus annum L. changes within single progenies and their relationships with plant development. Theor Appl Genet 85: 506-512.

Paun O, Fay MF, Soltis DE, Chase MW (2007). Genetic and epigenetic alterations after hybridization and genome doubling. Taxon 56: 649-656.

Piegu B, Guyot R, Picault N, Roulin A, Saniyal A, Kim H et al. (2006). Doubling genome size without polyploidization: dynamics of retrotransposition-driven genomic expansions in Oryza australiensis, a wild relative of rice. Genome Res 16: 1262-1269.

Price HJ, Johnston JS (1996). Influence of light on DNA content of Helianthus annuus Linnaeus. Proc Natl Acad Sci USA 93: 11264-11267.

Price HJ, Morgan PW, Johnston JS (1998). Environmentally correlated variation in $2 \mathrm{C}$ nuclear DNA content measurements in Helianthus annuus L. Ann Bot 82 (Suppl. A): 95-98.

Puchta H, Swoboda P, Hohn B (1995). Induction of intrachromosomal homologous recombination in whole plants. Plant I 7: 203-210.

Ries G, Heller W, Puchta H, Sandermann H, Seldlitz HK, Hohn B (2000). Elevated UV-B radiation reduces genome stability in plants. Nature 406: 98-101.

Sacerdot C, Mercier G, Todeschini AL, Dutreix M, Springer M, Lesage $P$ (2005). Impact of ionizing radiation on the life cycle of Saccharomyces cerevisiae Ty1 retrotransposon. Yeast 22: 441-455.

Schneeberger RG, Cullis CA (1991). Specific DNA alterations associated with the environmental induction of heritable changes in flax. Genetics 128: 619-630.

Spradling AC, de Cicco DV, Wakimoto BT, Levine JF, Kalfayan LJ, Cooley L (1987). Amplification of the X-linked Drosophila 
chorion gene cluster requires a region upstream from the s38 chorion gene. EMBO J 6: 1045-1053.

Stergiou G, Katsiotis A, Hagidimitriou M, Loukas M (2002). Genomic and chromosomal organization of Ty1copia-like sequences in Olea europaea and evolutionary relationships of Olea retroelements. Theor Appl Genet 104: 926-933.

Temsch EM, Greilhuber J (2001). Genome size in Arachis duranensis: a critical study. Genome 44: 826-830.

Wang X, Shi X, Hao B, Ge S, Luo J (2005). Duplication and DNA segmental loss in the rice genome: implications for diploidization. New Phytol 165: 937-946.

Waters ER, Schaal BA (1996). Heat shock induces a loss of rRNA-encoding DNA repeats in Brassica nigra. Proc Natl Acad Sci USA 93: 1449-1452.

Wyngaard GA, Rasch EM, Manning NM, Gasser K, Domangue R (2005). The relationship between genome size, development rate, and body size in copepods. Hydrobiologia 532: 123-137. 